\title{
Occupant-Centred Control strategies for Adaptive Facades: A preliminary study of the impact of shortwave solar radiation on thermal comfort
}

\author{
Alessandra Luna Navarro ${ }^{1}$, Juan Diego Blanco Cadena ${ }^{2}$, Fabio Favoino ${ }^{3}$, Mattia Donato ${ }^{4}$, Tiziana \\ Poli $^{2}$, Marco Perino ${ }^{3}$, Mauro Overend ${ }^{1}$ \\ ${ }^{1}$ Department of Engineering, University of Cambridge, UK \\ ${ }^{2}$ Architecture, Built Environment and Construction Engineering, Politecnico di Milano, Italy \\ ${ }^{3}$ Department of Energy, Politecnico di Torino, Italy \\ ${ }^{4}$ Façade Engineering, Arup, London, UK
}

\begin{abstract}
Adaptive facades have the potential to shape resourceefficient and occupant-centred spaces only when their control strategies are tailored to meet transient, local and personal demands. State-of-the-art control algorithms are currently failing to provide occupant thermal satisfaction because the data on occupant response to the thermal environment is not sufficiently granular. This paper presents a preliminary assessment of the use of the adjusted operative temperature, which accounts also for the additional effect of shortwave radiation on occupants, to dynamically devise learning control strategies that meet individual occupant comfort requirements. Shortwave effects of solar radiation on occupant comfort and operative temperature are compared to those considering only longwave radiation and two alternative occupantcentred control strategies are devised and assessed. Lastly, a combined occupant-centred control strategy is also proposed for an open space office.
\end{abstract}

\section{Introduction}

Glass facades have a crucial impact on occupant environmental satisfaction due to their daylighting and view potential, but they are also often associated with poor indoor environmental quality in perimeter zones of commercial buildings (Aries et al., 2010) due to glare or thermal discomfort. Adaptive facades have the potential to provide optimal indoor environmental condition whilst minimising energy consumption (Favoino et al., 2016; Liu et al., 2015). However, effective control strategies for maximising daylight while preventing occupant thermal discomfort or glare have yet to be achieved (Konis \& Selkowitz, 2017). One of the reasons why this occurs is the lack of high resolution data in time and space that captures the occupant transient environmental preferences (Konis \& Selkowitz, 2017). In order to capture actual thermal preferences of occupants in indoor environments with glass facades, it is essential to quantify: 1) radiant temperature effect on occupants, affecting both global thermal comfort and local discomfort, i.e. difference between façade and interior surface temperatures (walls, ceiling or floor); 2) effects of direct solar radiation on occupants, transmitted through the glazed façade.

Recent research has investigated effective occupantcentred control strategies for thermal comfort. Ajaji and André (2015) evaluated the effect of a control strategy based on maximum level of vertical irradiance on indoor operative temperature according to the EN 15251. A similar approach was adopted by Liu et al. (2015) and experimentally by Karlsen et al. (2015). Zarkadis and Morel (2013) investigated the effect of a novel predictive control strategy on thermal comfort using Fanger's model (Fanger, 1982) based on experimentally measured Mean Radiant Temperature (MRT) and the room air temperature. Similarly, Park and Augenbroe (2013) developed a control strategy that accounts for occupant thermal comfort using Predicted Percentage Dissatisfied (PPD). However, two main research gaps remain on the path of occupant-centred effective control strategies for transparent adaptive facades, namely: 1) uncertainties on the selection of thermal environmental control parameters and their optimal operating range; 2) methods for capturing the individual variations of personal environmental expectations or preferences, especially when conflictive scenarios arise (e.g. glare vs daylight). One of the main challenges to address these two issues, is that the environmental conditions (e.g. air and radiant temperature, direct solar radiation on occupant etc.) behind transparent façades are highly dynamic and unsteady.

Within these environments, there is often a mismatch between existing thermal performance indices (Bellia et al., 2017). This is due to the fact that steady-state and uniform modelling approaches to thermal comfort are unable to accurately assess façade performance since: glass façades deliver strong asymmetrical conditions (Carmody et al., 2004) and transient effects due to fluctuations in outside temperature and solar radiation, which produces high-frequency variation on surface temperature and transmitted solar radiation (Tzempelikos et al., 2010). Consequently, comfort indices for transient and non-uniform environments are required to evaluate such spaces, but they are usually time-consuming (Arens et al., 2015). In addition, thermal comfort models should also consider the effect of direct solar radiation on the occupant thermal comfort.

Currently, only few methods exist that account for the effect of direct solar radiation on occupants (Sullivan, 1986; La Gennusa et al, 2007; Karlsen et al. 2014; Arens et al. 2015; Zhang et al, 2018). These models are all based on the approach of adding the effect of the solar radiation to the original un-irradiated thermal sensation based on the PMV (Fanger, 1982). Among these methods, only 
Arens (2015) has been included in a standard (ANSI/ASHRAE 55, 2017).

One of the challenges of adopting these methods within a design workflow is the limitation of the radiosity method included in most Building Performance Simulation tools for predicting solar beam position inside a room, which is fundamental to correctly evaluate the effect of direct solar beam radiation on interior room surfaces and on the noncylindrical body shape (Arens et al., 2015). These difficulties prevent to accurately account the impact of direct solar radiation on occupant thermal comfort. This can result in a limited evaluation of the multi-domain impact of control strategies for the modulation of solar radiation on occupant comfort (by means of adaptive facades and smart glazing), traditionally considered as more determinant for visual comfort than thermal comfort criteria (Dussault \& Gosselin, 2017). ASHRAE 55-2017 suggests two approaches for predicting the impact of solar radiation on comfort conditions. The first approach is based on the work of Arens et al. (2015), where the effect of direct solar radiation $E_{\text {solar }}$ on the occupant skin and, hence, thermal sensation and comfort, is computed as an equivalent increase of Effective Radiant Field (ERF) (1) and, subsequently, of $M R T$ (2) and this is then added to the long-wave MRT (Appendix C, ASHRAE 55-2017) to estimate the overall adjusted Mean Radiant Temperature $\left(M R T^{*}\right)$ at the occupant position (3). The thermal sensation is then computed in terms of PMV according to $M R T^{*}$.

$$
\begin{aligned}
& E R F=\frac{\alpha_{s w}}{\alpha_{l w}} E_{\text {solar }} \\
& \Delta M R T=\frac{E R F}{f_{\text {eff }} h_{r}} \\
& M R T^{*}=\Delta M R T+M R T
\end{aligned}
$$

Where $f_{\text {eff }}$ is the fraction of the body surface exposed to radiation, $\alpha_{L w}$ is the skin long-wave absorptivity and $\alpha_{s w}$ is the skin short-wave absorptivity. The second approach proposed by ASHRAE 55-2017 is instead a simplified one, which assumes the $M R T$ is within a range of 2 to 8 ${ }^{\circ} \mathrm{C}$ above the average air temperature (based on the direct solar radiation). This is only valid under certain conditions, not usually applicable when occupants are exposed to large glazed surfaces. Moreover, accounting for the solar radiation transmitted through a transparent façade and incident on a human subject is not a trivial task, due to: i) the complexity on how this solar radiation is transmitted through the façade (due to obstructions, external/internal solar shading, complex transmission / absorption / reflection characteristics of the transparent element); ii) the directionality and position-dependency of the problem. Zani et al. (2018) have recently proposed a simulation workflow for static transparent facades using the first approach described by ASHRAE 55-2017, but evaluating the solar radiation incident on the occupant using an accurate backward raytracing method, thereby overcoming the above mentioned issues. To this end the DC method in the Radiance Simulation Engine was used to compute the total solar radiation incident on an occupant modelled with high geometrical accuracy.
The present paper aims to: i) evaluate the longwave and shortwave effect of solar radiation on operative temperature in the test case scenario of an office space with large transparent surfaces; ii) control the solar radiation influx through the transparent façade by means of switchable glazing to maintain the operative temperature within a comfort range; iii) devise a multioccupant centred control strategy for the switchable glazing of the test case scenario, based on the thermal sensation of each occupant, considering their position and orientation.

\section{Methods}

In order to account for direct solar radiation on the thermal sensation of occupants, the model developed by Arens et al. (2015) and implemented in the ASHRAE 55:2017 (ANSI/ASHRAE, 2017) was adopted, as per equations (1), (2) and (3). Therefore, the $T_{o p}$ is computed first, considering only the long-wave $M R T$, secondly the $E R F$ and the $\triangle M R T$ due to direct solar radiation is calculated and summed to $M R T$ to obtain the corrected $M R T^{*}$ (hence the corrected $T_{o p} *$ ) for each occupant.

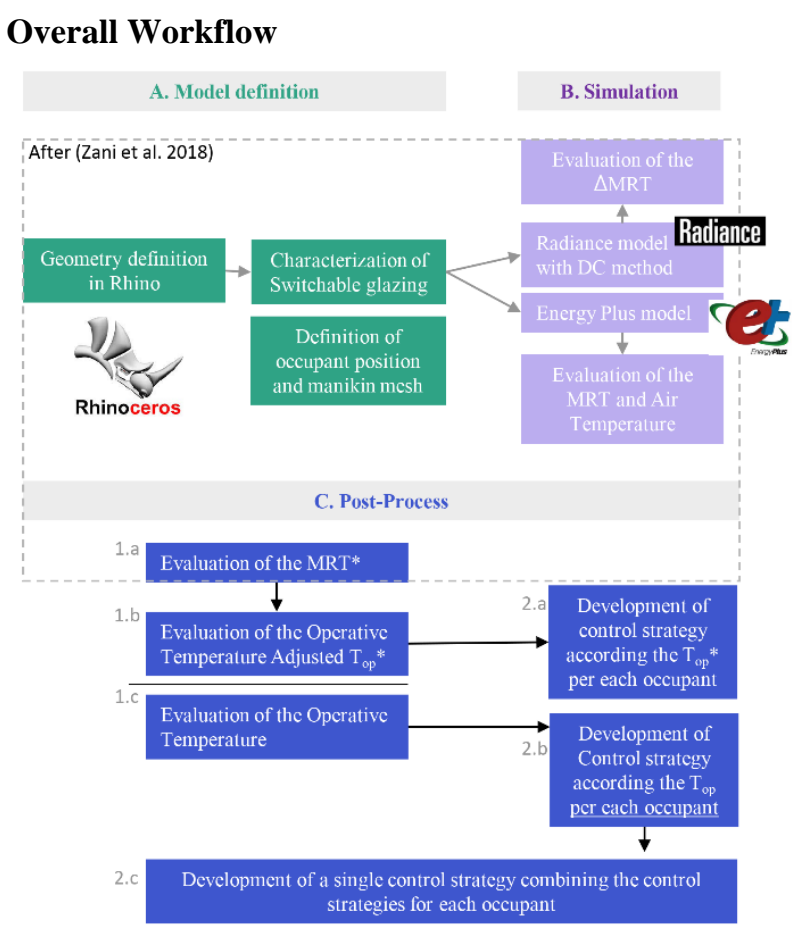

Figure 1: Overall workflow

Figure 1 describes the workflow followed in the present paper to devise control strategies of a switchable glazing based on thermal comfort considering the effect of direct solar radiation. This workflow consists of: A) defining the geometry, the materials and the occupant position and characteristics in Rhino; B) implementing the model in Radiance and Energy Plus simulation engines to compute $M R T, \triangle M R T$ (due to direct solar radiation) and the air temperature for each time step; C) evaluating the $T_{o p}$, the $M R T^{*}$ and the $T_{o p}{ }^{*}$ at each timestep, in post-processing.

Steps A, B and C were implemented following the simulation workflow proposed by Zani et al. (2018) and adapting it to a switchable glazing (SW) as follows: For 
the model definition (Step A), the geometry of test case scenario was developed in Rhino and, subsequently in Step B, two models in Radiance and Energy plus were implemented reproducing the same geometrical configuration through Grasshopper. From this, five different models for each SW are generated, each one representing a single state to which the switchable glass can be set. The $T_{o p}$ of the un-irradiated occupant for each single glazing state is calculated from the single EnergyPlus models, and the $\triangle M R T$ due to the direct solar radiation through the glazing is evaluated by means of the Radiance models. The final corrected $T_{o p} *$ is computed by adding in post-processing the $\triangle M R T$, due to direct solar radiation for each single state, to the corresponding $M R T$.

\section{Test scenario and thermal comfort criteria}

The test scenario is a living lab in Cambridge (UK) called MATELab (Luna-Navarro et al., 2018). MATELab is an office space of approximately 30 square metres, with a South-oriented adaptive glass facade and a Window-toWall Ratio (WWR) of $\sim 0.5$. The laboratory has a raised floor which reaches the lower edge of the glazing's frame, enabling a simplified digital model. The characteristics of the building envelope are summarised in Table 1.

Table 1: Characteristics of the Building Envelope.

\begin{tabular}{|l|l|l|l|}
\hline Element & $\begin{array}{l}\text { Overall } \\
\mathbf{U - v a l u e} \\
{\left[\mathbf{W} / \mathbf{m}^{2} \mathbf{K}\right]}\end{array}$ & SHGC & $\begin{array}{l}\text { Indoor } \\
\text { reflectance }\end{array}$ \\
\hline Floor & 0.20 & - & 0.20 \\
\hline Ceiling & 0.16 & - & 0.70 \\
\hline $\begin{array}{l}\text { Opaque } \\
\text { wall }\end{array}$ & 0.20 & - & 0.70 \\
\hline $\begin{array}{l}\text { Glass } \\
\text { facade }\end{array}$ & 1.2 & $\begin{array}{l}0.148- \\
0.475\end{array}$ & \\
\hline
\end{tabular}

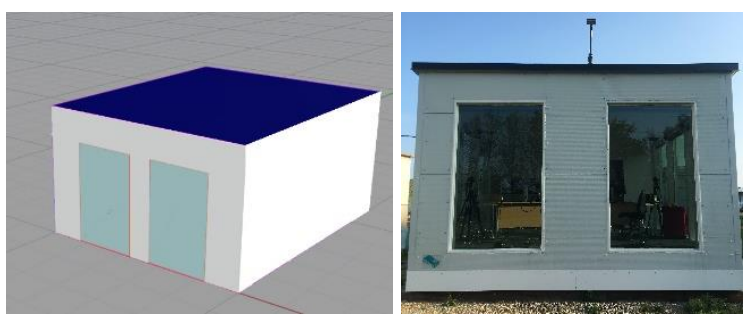

Figure 2: View of MATELab: the test scenario (left) and real case scenario.

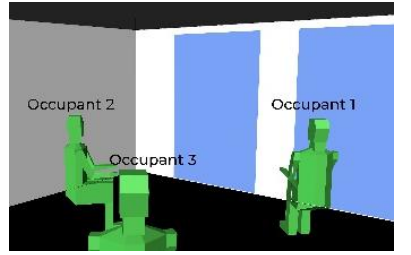

(a)

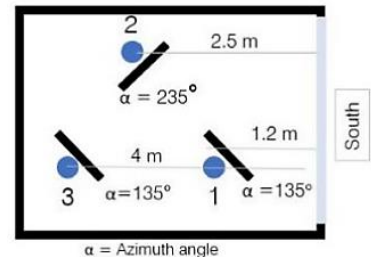

(b)
Figure 3: View of the test scenario analysed (a) Perspective inside, (b) Floor plan - occupant location.

The test case scenario was chosen since it is a dedicated space for in situ multi-domain assessment of occupant response to alternative control strategies for adaptive facades. This test case scenario offers the possibility of experimentally validating the simulation results against real scenarios and actual occupant response. MATELab hosts three occupants at a fixed position and distances from the south façade for the specific test case scenario. Each occupant is oriented $45^{\circ}$ with respect of the south façade (i.e. azimuth orientation of $135^{\circ}$ for occupant 1 and 3 , and $235^{\circ}$ for occupant 2 ) and located at a distance of $1.20,2.50$ and $4 \mathrm{~m}$ from the façade, respectively (see Figure 2).The stated occupant orientation was decided to explore alternative scenarios of body exposure to solar radiation and in order to be coherent with the original setup of the test facility, which follows the layout reported by Christoffersen and Wienold (2006).

The adaptive facade is a switchable glazing with 5 possible states, characterised by a different solar and light transmittance (Table 2).

Table 2: Characteristics of the Adaptive Façade.

\begin{tabular}{|l|l|l|l|l|}
\hline $\begin{array}{l}\text { Glass } \\
\text { state }\end{array}$ & $\mathbf{T}_{\text {sol }}$ & $\mathbf{T}_{\text {vis }}$ & SHGC & $\begin{array}{l}\text { U-value } \\
{\left[\mathbf{W} / \mathbf{m}^{2}\right]}\end{array}$ \\
\hline 1 & 0.02 & 0.021 & 0.148 & 1.2 \\
\hline 2 & 0.14 & 0.129 & 0.186 & 1.2 \\
\hline 3 & 0.28 & 0.251 & 0.238 & 1.2 \\
\hline 4 & 0.46 & 0.413 & 0.321 & 1.2 \\
\hline 5 & 0.73 & 0.66 & 0.475 & 1.2 \\
\hline
\end{tabular}

Key environmental parameters for thermal comfort are: air velocity, air temperature, humidity, $M R T$ and direct solar radiation on the occupant $\left(I_{d i r}\right)$. The longwave thermal exchange of the occupant is defined by the fraction of the body surface exposed to radiation $\left(f_{\text {eff }}\right)$ and the skin long-wave absorptivity $\left(\alpha_{L w}\right.$. $)$ In addition, the following input values are needed to define the thermal effect of glass facades on occupant: fraction of the body exposed to solar beam, sky vault view fraction and shortwave absorptivity $\left(\alpha_{s w}\right)$. The first two parameters were computed within the simulation workflow, while $\alpha_{s w}=0.67, \alpha_{L w}=0.95$ and $f_{\text {eff }}=0.696$ are used as constant values for computing the $\triangle \mathrm{MRT}$ as suggested by Arens et al. (2015). The operative temperature $T_{o p}$ can be defined as the average of the mean radiant and ambient air temperatures, weighted by their respective heat transfer coefficients (4) and it is useful thermal parameter when studying the overall sensible thermal exchange of occupants in the environment. The use of the $T_{o p}$ as a façade control parameter and the adjusted version $T_{o p} *(5)$ were investigated in this study. The latter was computed using the adjusted $M R T^{*}$, considering the radiative heat transfer coefficient $h_{r}$ and the convective heat transfer coefficient $h_{c}$

$$
\begin{aligned}
& T_{o p}=\frac{h_{r} M R T+h_{c} T_{a}}{h_{r}+h_{c}} \\
& T_{o p}{ }^{*}=\frac{h_{r} M R T^{*}+h_{c} T_{a}}{h_{r}+h_{c}}
\end{aligned}
$$

The $T_{o p} *$ depends on the occupant position and orientation of the occupant relatively to the sun since it includes the $\triangle M R T$, which is computed according the actual area of the occupant exposed to direct solar radiation. Transparent façades usually induce larger thermal asymmetries and transient environmental conditions due to fluctuations in solar radiation and surface temperatures. The use of the 
PMV (Fanger, 1982) on its own is not appropriate in this case, since it does not account for these effects. Instead the approach suggested by Arens et al. (2015) was implemented, in order to adjust the PMV to take into account direct solar radiation on occupants. The effect of solar radiation was considered as an increase in occupant $M R T$, and the overall PMV adjusted accordingly. In this work, the range of acceptable adjusted PMV was set between -0.5 and 0.5 , given that Relative Humidity (RH) $(50 \%)$ and air speed $(0.1 \mathrm{~m} / \mathrm{s})$ are modelled as constant, the boundaries of the comfort zone were set in terms of $T_{o p}$. Occupants are considered to perform activities with metabolic rates lower or equal to $1.2 \mathrm{Met}$ and level of clothing between 0.5 clo (Summer condition) and 1 clo (Winter condition). Table 3 shows the threshold $T_{o p}$ values considered.

Table 3: Threshold of maximum and minimum Top.

\begin{tabular}{|l|l|l|}
\hline \multicolumn{1}{|c|}{ Season } & Maximum $\mathbf{T}_{\text {op }}$ & Minimum $\mathbf{T}_{\text {op }}$ \\
\hline Winter & $23.9^{\circ} \mathrm{C}$ & $19.2^{\circ} \mathrm{C}$ \\
\hline Summer & $26.4^{\circ} \mathrm{C}$ & $23{ }^{\circ} \mathrm{C}$ \\
\hline
\end{tabular}

\section{Simulation procedure and models}

Simulations in Energy plus (v 9.0.1) and Radiance (v 5.2) were performed to obtain hourly results for each state of the glass. In the present paper only two representative months are reported, one in winter (February) and one in summer (August). This is due to the time required ( $3-5$ min per timestep) to perform suitable Radiance simulations to account for the direct solar radiation on the 3 manikins, future work will aim to reduce the computational time of this method and perform complete yearly simulations. The radiance method selected was the Daylight Coefficients method, and the key parameters used for setting the radiance engine were: -aa 0.05, -ar 300 and -ab 4. Sufficient ambient bounces were required, as both direct and diffuse radiation components are needed. The window transmittance function followed the dielectric radiance material definition, with an index of refraction of 1.52. On the other hand, the EnergyPlus model glazing describes the transmittance function based on correlations between the U-value and the SHGC. For this model, in addition to the settings shown in Table 3, the following attributes were used:

- Cooling setback temperature $=30^{\circ} \mathrm{C}$;

- Heating setback temperature $=16^{\circ} \mathrm{C}$;

- $\mathrm{RH}=50 \%$;

- Occupancy schedule set to Medium Office Bldg Occ ( 6:00-20:00);

- Ventilation rate $=0.2 \mathrm{~m} / \mathrm{s}$;

- Internal gains $=6.89 \mathrm{~W} / \mathrm{m}^{2}$;

- $\quad$ Ground Temperature $=18{ }^{\circ} \mathrm{C}$;

- 6 timestep per hour for energy balance calculations.

The manikin in the Radiance model is the same as the one used by Arens et al. (2015), with 481 faces drawing the human body's shape, with a total area of $\sim 1.83 \mathrm{~m}^{2}$, on a seated position placed as stated in the Test scenario. The $M R T$ within EnergyPlus was calculated by analysing the radiative environment on three nodes placed at the bodycentre of the manikin. Then, the $E_{\text {solar }}$ was obtained at every hour by weighting the total radiance received by a manikin's face and its area, divided by the total manikin area; followed by the $\triangle M R T$ calculation using equation (1) and (2).

\section{Thermal comfort based switchable glazing control}

Based on the thermal comfort criteria set, two alternative occupant-centred control strategies were developed for the façade, to control the solar radiation and maintain each occupant within a range of comfortable operative temperatures:

1) Control Strategy 1 (CS1) was defined using the $\mathrm{T}_{\text {op }}$ as control parameter

2) Control Strategy $2(\mathrm{CS} 2)$ using the $T_{o p}{ }^{*}$.

Both control strategies select the most transparent glass state that maintains the control parameter $\left(T_{o p}\right.$ or $\left.T_{o p} *\right)$, for each occupant, within the comfort boundaries (i.e. below the upper threshold of operative temperature of $23.9^{\circ} \mathrm{C}$ in Winter and $26.4^{\circ} \mathrm{C}$ in summer). The control strategies are intended to be occupant-centred, hence their effects on the overall room thermal conditions are not considered and in this test case scenario only three fixed occupant positions were studied. A final collective control strategy is then proposed to minimise discomfort among all occupants, combining the control strategies for each occupant.

In the preliminary assessment presented in this paper, simulations are performed separately for each state of the switchable glazing and then the optimal state is selected in post-processing stage. Thus, transient effects due to the previous thermal history are not considered, thereby leading to possible mismatch between actual $T_{o p}$ and indicated one.

\section{Results and Discussion}

The preliminary assessment analyses the thermal environmental conditions in a winter month (February) and in one summer month (August). Figure 4 shows the differences in $T_{o p}$ and $T_{o p} *$ for each occupant during a day in February and in August. It is shown that accounting for the shortwave effects of the direct solar radiation on the occupants, increases occupants $T_{\mathrm{op}}$ and, consequently, shifts the operative temperature out of the comfort range. Shortwave effects of solar radiation on occupant comfort are clearly more noticeable when the solar transmittance of the glass is higher, along with the amount of solar radiation falling on the occupants. Because of different orientation and proximity to the façade, the occupants are uniquely affected by the shortwave radiation. The occupant closer to the façade (Occupant 1) is more sensitive to solar radiation effects in Summer, when the solar beam trayectory is more vertical, while other occupants are affected by the direct solar radiation in winter, when the sun is lower and the penetration depth of the sun rays is larger. The shortwave effects of the transmitted solar radiation on $T_{o p}$ are strongly correlated with the distance of the occupant from the façade but especially with the occupant orientation, dependending on the season and the penetration depth of the solar ray; while only longwave Operative Temperature $T_{o p}$ shows stronger dependency on occupant distance rather than orientation. 

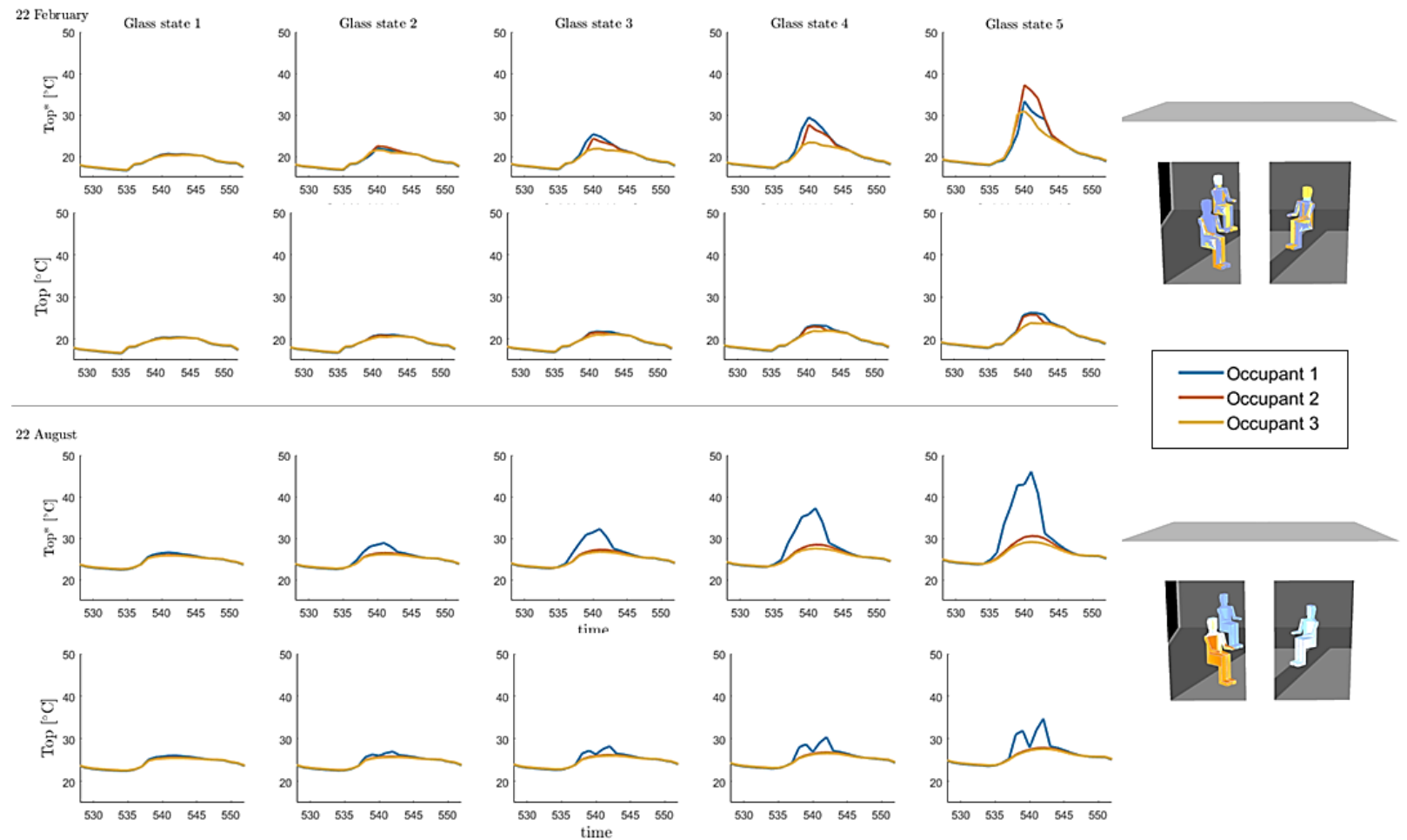

Figure 4: Adjusted Operative Temperature $T_{o p} *$ and simple Operative Temperature of the three occupants over the 22 of February and the 22 of August. On the right, the solar radiation on the manikin surface is shown at $12 \mathrm{pm}$.

Larger distances form the façade make less noticeable these discrepancies, being the distant occupants the ones less affected by the thermal effects of the transparent facade.

Two alternative control strategies were then developed with $T_{o p}$ and $T_{o p}{ }^{*}$ as control parameters for respectively Control Strategy 1 (CS1) and Control Strategy 2 (CS2) and independently for each occupant. Control strategies are reported in Figure 5 and Figure 6 in terms of glass state (graphs in Figure 5(a) and (b), Figure 6(a) and (b)), together with the respective $T_{o p}{ }^{*}$ for each occupant and individual control strategy (graphs in Figure 5(d) and (e), Figure 6(d) and (e)) and for a static glass equivalent to the state 4 (graphs Figure 5(c) and Figure 6(c)). As a consequence of the lower levels of $\mathrm{T}_{\text {op }}$ than the adjusted one, CS1 provides larger transparency. This is in agreement with previous research (Dussault \& Gosselin, 2017) who reported lower sensitivity of Control Strategies to thermal comfort requirements. However, when accounting for the shortwave effects, as shown in CS2, darker states of the glass are needed to maintain the $\mathrm{T}_{\mathrm{op}} *$ under the upper comfort threshold. This is particularly noticeable in winter, when the sun penetration depth is larger and occupants are more affected by shortwave rather than longerwave solar radiation. Figure 5(d) and Figure 6(d) shows the variation of $T_{o p}$ * (considering the effect of short-wave solar radiation), when the control strategy CS1 is applied, which has been designed without accounting for direct solar radiation; withal, the $T_{o p}{ }^{*}$ obtained for this control strategy produced, is well above the comfort range, if one considers the effect of direct solar radiation.

All the control strategies reported in Figure 5 and Figure 6 are occupant-centred and not applicable to a multi-occupant space. However, an overall Control Strategy can be proposed to minimise thermal discomfort for all occupants. Figure 7 and Figure 8 show the combined control strategy for the 3 occupants, using, for each time step, the more transparent glass state that mantains the $\mathrm{T}_{\mathrm{op}}$ * under the comfort threshold for all the occupants. Comparing Figure 5, Figure 6, Figure 7(a) and Figure 8 (a), in Summer the Combined Control Strategy is governed by the thermal comfort of Occupant 1 (closer position to the façade), while in Winter Occupant 2, who is oriented towards west, has a more signifiant influcence. These considerations are closely related to the given test case scenario and sensitive to boundary conditions such as: Window-ToWall ratio, office layout etc. Figure 7 (b) and Figure 8 (b) show the value of the external irradiance on the facades and relative glass state per each time step on the $10^{\text {th }}$ of February and the $22^{\text {nd }}$ of August respectively. Same levels of irradiance correspond to different glass states since the level of $T_{o p} *$ are different. However, if appropriate correlations are found between occupant thermal sensation and external irradiance, depending on the occupant position and orientation, this would lead to simpler control parameters for occupant-centred thermal control strategies based on intensity of solar radiation and solar geometry. 


\section{Conclusion and future work}

The use of the adjusted Operative Temperature $\left(T_{o p}{ }^{*}\right)$ as a control parameter for occupant-centred control strategies for solar radiation modulation by means of a smart glazing for thermal comfort was assessed in a preliminary study. Shortwave effects were shown to have a strong impact on thermal comfort, hence on defining satisfactory control strategies for solar radiation control. At the same time not accounting for the effect of direct solar radiation on the thermal comfort for the control of switchable glazing, could result in critical overheating issues (particularly in winter, also at a significant distance from the facade). In fact, the impact of direct solar radiation is highly dependent on occupant positions and respective incidence angle of the solar gain. Different occupant location and orientation, with respect to the façade, was shown to have a strong effect on the local $T_{o p}$ *, thereby highlighting the importance of simulation for devising a suitable learning control strategy. However, further assessments are required to explore how best to use simulations for fitting control strategies to local requirements and individual expectations, and to provide a method for elaborating a simple, yet effective, control strategy for a particular environment.

The effects of thermal history arising from previous glass states should in future also be included in the simulation workflow to accurately define satisfactory control strategies according to the adjusted $T_{o p}{ }^{*}$. In addition, since facades have a multi-domain effect on occupants, there is a need to account for and aggregate the differing visual and thermal requirements of each occupant. Future work will therefore expand the simulation workflow to include visual comfort evaluation. In addition, comfort thresholds need to be defined using a comfort model that can accurately predict the occupant response to transient and asymmetrical glass façade effects.

Lastly, future research will include experimental work to validate the thermal and optical models and to assess occupant response to control strategies based on $T_{o p} *$ as thermal control parameter. This will ascertain whether the vertical irradiance on the façade, with the local $T_{o p} *$ are correlated, and will provide actual occupant responses that are essential for devising optimal control strategies for occupant-centred resource-efficient buildings.

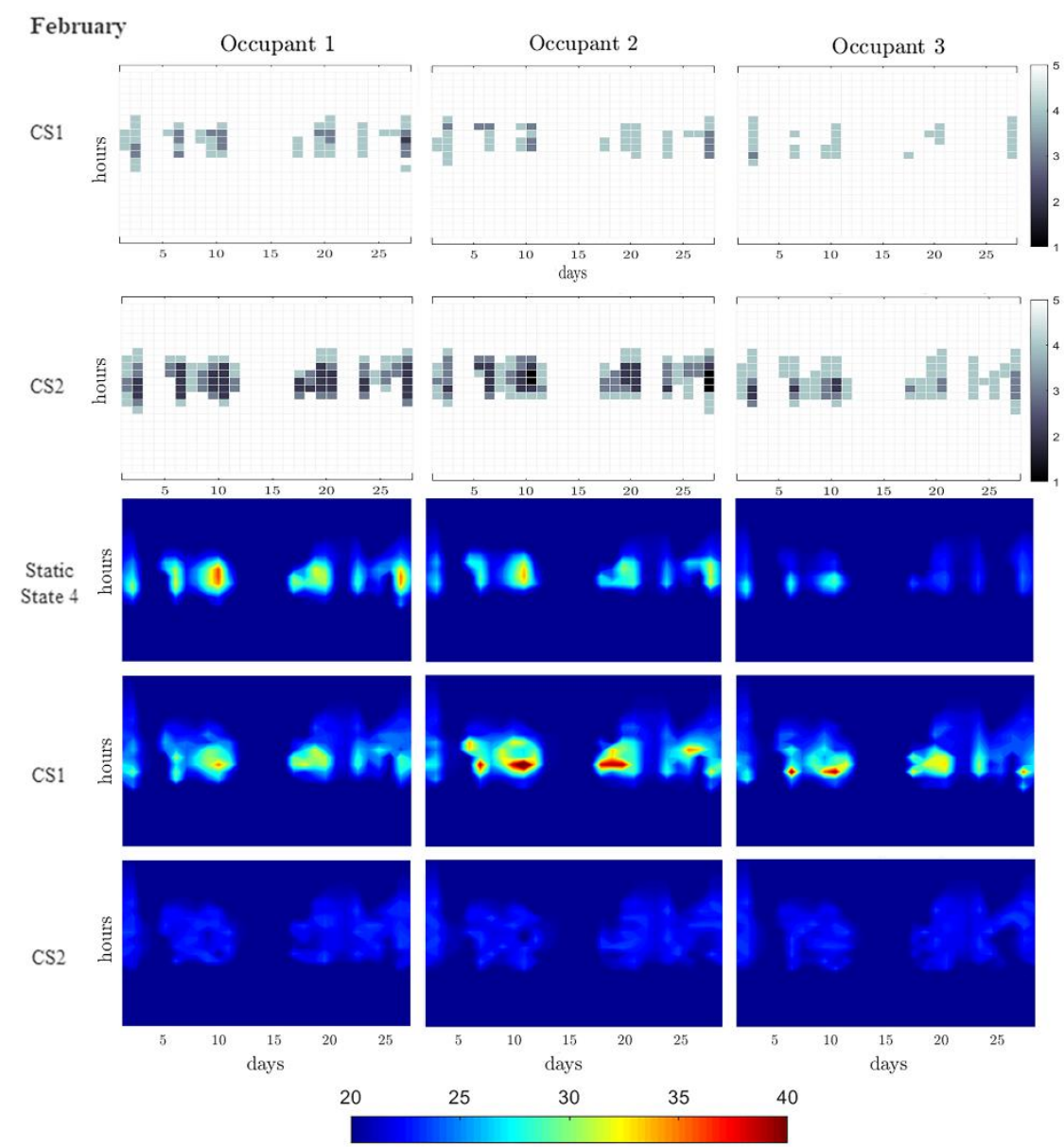

Figure 5: Carpet plots of the switchable glazing activation Control Strategies (on top) and Top* for each occupant under three different glass states: static glass on state 4, Switchable glazing with CS1 and CS2 (on bottom) during February. 


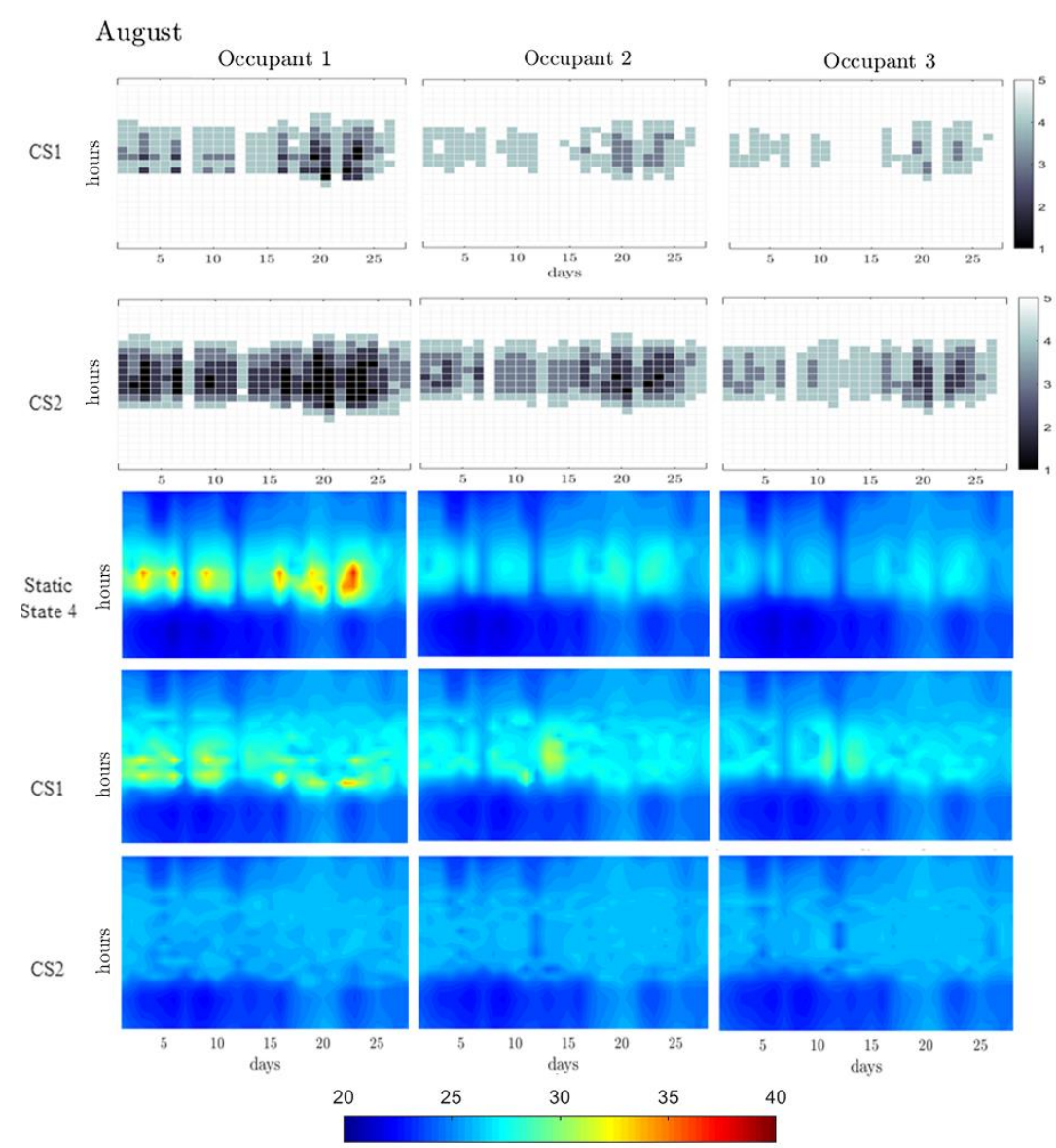

Figure 6: Carpet plots of the switchable glazing activation Control Strategies (on top) and Top* for each occupant under three different glass states: static glass on state 4, Switchable glazing with CS1 and CS2 (on bottom) during August.

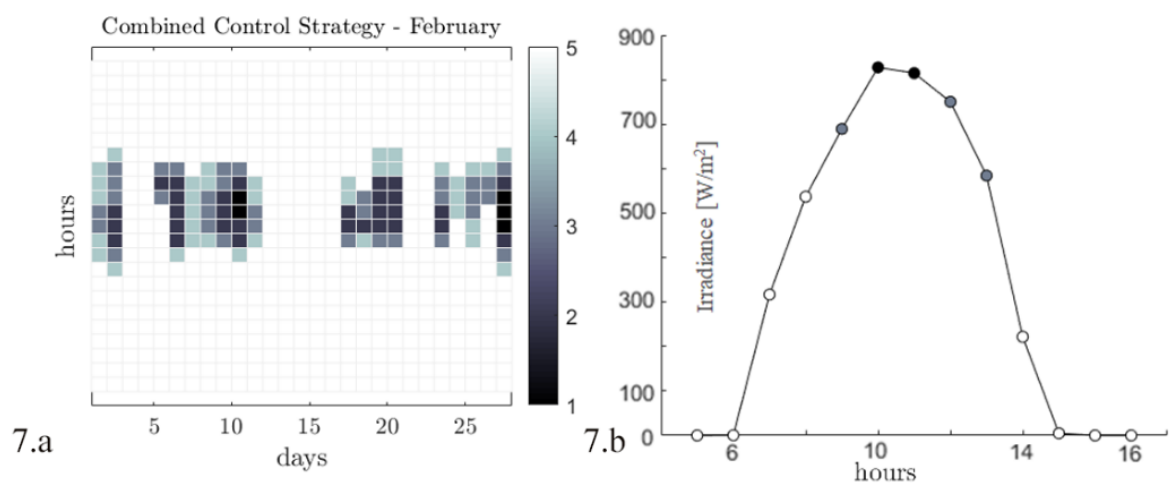

Figure 7: Combined Control Strategy for August (a) and Glass State and Irradiance during the 10 February (b).
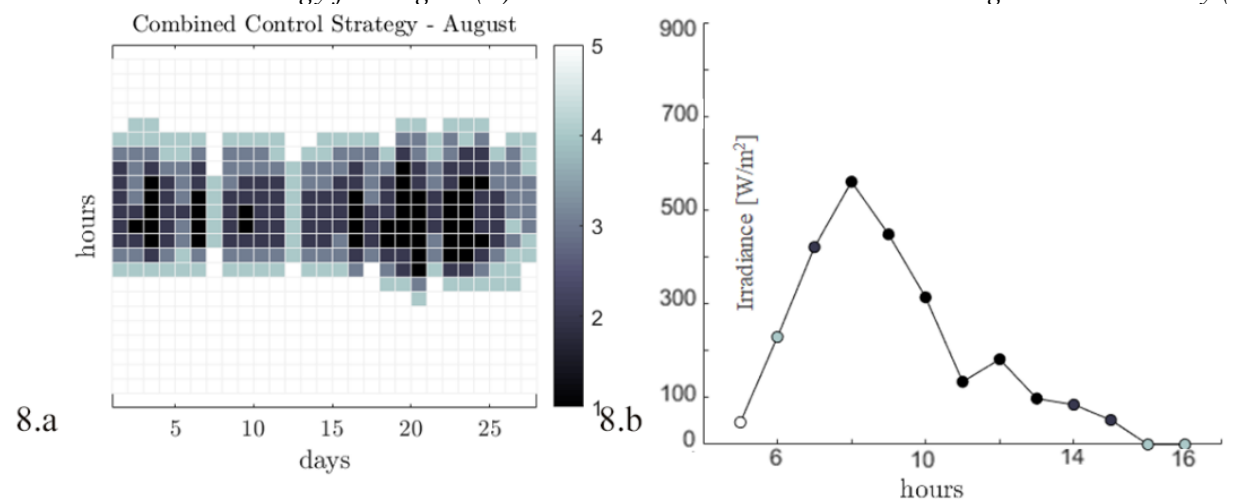

Figure 8: Combined Control Strategy for August (a) and Glass State and Irradiance during the 22 August (b). 


\section{Acknowledgement}

The UK authors acknowledge the support of EPSRC, Arup and Permasteelisa.

\section{References}

ANSI/ASHRAE. (2017). ANSI/ASHRAE 55:2017 Thermal Environmental Conditions for Human Occupancy.

Arens, E., Hoyt, T., Zhou, X., Huang, L., Zhang, H. and Schiavon, S. (2015). Modeling the comfort effects of short-wave solar radiation indoors. Building and Environment, 88, 3-9.

Aries, M. B. C., Veitch, J. A. and Newsham, G. R. (2010). Windows, view, and office characteristics predict physical and psychological discomfort. Journal of Environmental Psychology, 30(4), 533541.

Bellia, L., Fragliasso, F. and Stefanizzi, E. (2017). Daylit offices: A comparison between measured parameters assessing light quality and users' opinions. Building and Environment.

Carmody, J., Selkowitz, S., Lee, E., Arasteh, D. and Willmert, T. (2004). Window systems for high performance buildings (First). New York: Norton.

Dussault, J. M. and Gosselin, L. (2017). Office buildings with electrochromic windows: A sensitivity analysis of design parameters on energy performance, and thermal and visual comfort. Energy and Buildings.

Fanger, P. O. (1982). Thermal Comfort. Technical Review (Vol. 2).

Favoino, F., Fiorito, F., Cannavale, A., Ranzi, G. and Overend, M. (2016). Optimal control and performance of photovoltachromic switchable glazing for building integration in temperate climates. Applied Energy, 178, 943-961.

Konis, K. and Selkowitz, S. (2017). Effective Daylighting with High-Performance Facades, 251269.

Liu, M., Wittchen, K. B. and Heiselberg, P. K. (2015). Control strategies for intelligent glazed façade and their influence on energy and comfort performance of office buildings in Denmark. Applied Energy, 145, 43-51.

Luna-Navarro, A., Meizoso, M., DeBleecker, H., Verhoeven, Y., Donato, M. and Overend, M. (2018). Façade impulse: experimental methods for stretching the envelope beyond human comfort. In VIII International Congress on Architectural Envelopes. San Sebastian.

Tzempelikos, A., Bessoudo, M., Athienitis, A. K. and Zmeureanu, R. (2010). Indoor thermal environmental conditions near glazed facades with shading devices - Part II: Thermal comfort simulation and impact of glazing and shading properties. Building and Environment, 45(11), 2517-2525.
Wienold, J. and Christoffersen, J. (2006). Evaluation methods and development of a new glare prediction model for daylight environments with the use of CCD cameras. Energy and Buildings, 38(7), 743757.

Zani, A., Mainini, A. G., Blanco Cadena, J. D., Schiavon, S. and Arens, E. (2018). A new modeling approach for the assessment of the effect of solar radiation on indoor thermal comfort. In 2018 Building Performance Analysis Conference and SimBuild co-organized by ASHRAE and IBPSAUSA. Chicago, IL. 